\title{
Novas Configurações das Eleições na Idade Mídia
}

\section{Antonio Albino Canelas Rubim}

Faculdade de Comunicação

Universidade Federal da Bahia

\section{Resumo}

No mundo contemporâneo, o surgimento e desenvolvimento da comunicação midiática, e a conformação de uma sociabilidade estruturada e ambientada pela mídia recolocam em intensa evidência a temática do relacionamento entre política e comunicação. A interação entre mídia e eleições é tomada aqui como emblemática das transformações.

Palavras-chave: mídia, eleições, comunicação, política

\section{Abstract}

In the contemporary world, the emergence and the development of a mediatic communication, and the conformation of a sociability structured by the media put in evidence the relationship between politics and communication. The interaction between media and elections is analyzed in this article as the emblematic example of these transformations.

Key words: media, elections, communication, politics 
O tema da relação entre eleições e mídia aparece hoje, sem dúvida, como um dos mais significativos para a compreensão das novas configurações assumidas pela política na contemporaneidade, concebida como Idade Mídia. A comunicação sempre esteve associada aos embates eleitorais. Desde que a política se constituiu como um modo específico de resolver a questão do poder político - conforme a perspicaz formulação de Castoriadis - na Grécia antiga por volta do século $V$ antes de Cristo essa interação acontece. Com a expansão e consolidação das eleições como procedimento e rito imprescindível à política na modernidade esse imbricamento se tornou ainda mais relevante. No mundo contemporâneo, o surgimento e desenvolvimento de uma nova modalidade de comunicação, aqui nomeada de midiática, e a conformação de uma sociabilidade estruturada e ambientada pela mídia recolocam em intensa evidência a temática do relacionamento entre política e comunicação, e, em especial, da interação entre mídia e eleições, pois eles resignificam em profundidade os termos envolvidos na relação, alterando de modo significativo as configurações dos processos eleitorais como se pretende demonstrar.

Cabe, antes disso, para a elucidação da temática, uma análise pormenorizada da singularidade política do momento eleitoral, de sua intrínseca conexão com a comunicação e uma interpretação atenta da também singular circunstância sóciocomunicacional que formata a atualidade. Tais procedimentos devem possibilitar uma compreensão fina das mutações em curso nas configurações das eleições e das novas conexões existentes entre comunicação e política, que conformam estes campos.

O estudo centrado nas interfaces entre os campos da comunicação e da política constitui-se um registro de horizonte compreensivo mais afinado para elucidar as mutações em curso na comunicação e na política, que as investigações antes predominantes da comunicação política, nas quais se realça o aspecto instrumental da comunicação e seu acionamento pela política, ou das políticas de comunicação, em voga nos anos 70 e 80, quando a ênfase recaía nos movimentos de reorganização societária das comunicações. Não que estas áreas percam importância acadêmica e interesse social, apenas se ressalta aqui um aspecto crucial, que tem sido menosprezado: a necessária compreensão mais abrangente das essenciais conexões contemporâneas entre os campos da comunicação e da política para desvelar as mutações em andamento nestes campos, as quais decorrem de uma interpenetração cada vez mais íntima entre eles. 


\section{Do sentido das eleições}

Parece razoável começar a reflexão por este dispositivo hoje quase natural(izado) da política: as eleições. Em uma primeira aproximação, pode-se supor as eleições como um momento e um procedimento - ritualizado, periódico e legitimado - de escolha e investidura de dirigentes (representativos) para exercício de poder(es) na sociedade. Assim as eleições se aproximam e se diferenciam de outros procedimentos de escolha e investidura como a herança, a nomeação, a coaptação, etc.

As eleições escolhem quem deve governar, quem vai ocupar lugares determinados de exercício de poder em instituições do Estado - sejam elas do exe-cutivo, do legislativo ou, em algumas países, do judiciário - ou da sociedade civil ou, em circunstâncias infinitamente menos comuns, devido ao seu caráter não democratizado, do mercado. Assim as eleições escolhem aqueles que estarão em lugares de comando. Isto é, em lugares e situações, em que se dispõe de modo privilegiado de parcela de poder para governar, inclusive porque têm a sua dispo-sição variados tipos de recursos que permitem viabilizar o governo na sociedade.

Mas essa escolha dos ocupantes dos lugares de poder não assegura a eles permanentemente o poder de governar. Primeiro porque a escolha quase sempre está associada a um mandato com tempo determinado. Segundo porque apenas coloca os escolhidos em lugar especial e privilegiado para poder começar a governar, mas não pode garantir que o poder de governar se mantenha durante o mandato. $\mathrm{O}$ ato de governar implica necessariamente em uma disputa cotidiana acerca do poder de governar. A governabilidade, entendida como conjunto de condi-ções políticas para governar, deve ser pensada como perpassada por um constante embate entre os ocupantes do governo e as oposições, sejam elas e elas partidos, políticos profissionais e/ou cidadãos. A dialética governo e oposição emerge assim como imprescindível para a realização de uma dinâmica democrática.

Esta distinção adquire sentido e importância, pois as eleições funcionam como procedimento social e fundamental de distribuição do poder de governar, periódico e de caráter momentâneo, pois, a rigor, esta distribuição transcende a excepcionalidade do episódio eleitoral, acontecendo ordinariamente através da persistente disputa do poder de governar, das condições de governabilidade. Assim a escolha e investidura, via eleições, propicia a ocupação dos lugares nos quais se concentra poder e define o programa vencedor, mas não pode assegurar, nem dar garantias plenas da realização deste projeto. Em situações democráticas, a governabilidade resulta desta permanente disputa do poder de governar.

Este momento e procedimento periódico de distribuição social de poder acontece porque em um regime democrático cada cidadão, pelo menos formalmente, detém uma parcela de poder, que se encontra formalmente pulverizado na sociedade. Através do instrumento do voto, o cidadão delega parte deste poder ao seu representante político, 
que, reunindo um conjunto necessário de votos, ganha representatividade para ser guindado a um lugar de governo (executivo, legislativo e, por vezes, judiciário) na sociedade. A idéia de representação - com todas as virtudes e defeitos que contém aparece aqui como em essencial para a política moderna e contemporânea.

As eleições, em plenitude, emergem como invenção moderna. Elas têm como exigências fundantes uma política que tem um princípio de legitimação secular pela via desse mecanismo de representação. O governo e os governantes tornam-se legítimos quando escolhidos através deste rito público. Tal condição de legitimidade, sempre necessária, entretanto não se apresenta como suficiente, pois as eleições devem asseguram garantias satisfatórias de competitividade aos concorrentes (partidos e candidatos). Além disto, a legitimidade de governo e governantes extrapola o instante eleitoral e decorre da efetiva transformação deles em representantes dos cidadãos, quando realizam (bem) os interesses públicos.

As lutas sociais, especialmente as do século $\mathrm{XIX}$ e $\mathrm{XX}$, conquistaram uma extensão da noção de cidadania, adstrita no início do período liberal clássico aos proprietários. Com isto, o sufrágio, antes censitário e elitista, tornou-se universal, primeiro para os homens e depois também para as mulheres na maioria dos países. Desta maneira, as lutas sociais dos trabalhadores e das mulheres fizeram das eleições um componente fundamental da política moderna, em sua fase tardia, e da contemporânea, em especial. Assim em situações democráticas as eleições competitivas aparecem como momentos e procedimentos essenciais de delegação, (re)distribuição e alternância do poder político na sociedade.

Caso as condições de disputa sejam (muito) desiguais o caráter competitivo das eleições fica vitalmente comprometido. Daí advém uma série de problemas. Um deles parece ser a concentração de poder que a desigualdade gera, fazendo com que a política (quase) se restrinja a alguns setores da sociedade, detentores privilegiados de outras modalidades de poder, em especial do poder econômico. Outro problema parece advir da diferenciada disponibilidade de dedicação à atividade política. Esta distorção faz que a política pareça ser um atributo de apenas uma parcela da sociedade, os políticos profissionalizados. Pierre Bourdieu, em sua análise do campo político, fala mesmo de um "monopólio dos profissionais". Sem menosprezar as possibilidades sociais de distorção ou esquecer o caráter também problemático da idéia de representação e dos procedimentos eleitorais, assediados na atualidade por diversas crises $^{1}$, pode-se afirmar as eleições como momento singular da política, em diversos sentidos.

As eleições - ao possibilitar e solicitar, através do acionamento do poder singular do cidadão, o envolvimento e decisão de todos, ainda que isto ocorra em termos episódicos e de maneiras muitas vezes pouco consistentes - obrigam a uma ampliação, mesmo momentânea, dos partícipes da política e permitem uma oxigenação do universo

\footnotetext{
${ }^{1}$ Por exemplo, TOURAINE (1996) especialmente nas páginas 76-92.
} 
político. Neste momento, ao menos, todos podem e devem fazer política, inclusive por solicitação expressa, legítima e legal da sociedade.

Mais que isto, se requer de todos uma avaliação - aceita as premissas do funcionamento eleitoral - do campo político e seus participantes mais cotidianos, em especial, os partidos e os profissionais da política. Tal julgamento viabiliza, em seqüência, justamente uma nova delegação de poderes. Em síntese, como observa Irlys Barreira em seu livro Chuva de papéis, possibilita uma renovação do pacto essencial de representação existente entre cidadãos e suas representações políticas (partidos e políticos profissionalizados). Representação e eleições viabilizam-se, assim, mutuamente.

Esta exigência de ampliação da participação na política, sem o que o processo eleitoral pode se tornar ilegítimo, e a disputa pública de poder levam normalmente a um certa aceleração do ritmo da política, característico das eleições. Tal temporalidade acelerada da política - também existente em circunstâncias de conflitos e rupturas sociais pronunciados e excepcionais - tem uma relação direta com a situação de disputa e a possibilidade de alternância dos ocupantes dos lugares de poder. Não por acaso, a aceleração do ritmo das eleições, por exemplo, guarda uma estrita sintonia com o grau de competitividade existente entre as forças que concorrem e a efetiva possibilidade de mudança dos governantes. Quanto mais competitiva, quanto mais o poder político está verdadeiramente em jogo, mas probabilidade uma eleição tem de despertar interesse da população e acelerar o ritmo político.

A mobilização das forças sociais e da cidadania, em geral, dependem deste grau de competitividade eleitoral, mas também decorrem deste caráter de tempo delimitado e específico para disputa de poder e da percepção social das eleições como instante no qual a interferência dos cidadãos se apresenta como mais viável. Neste momento parece mais possível fazer valer a cidadania e seu poder, ainda que, muitas vezes, tal percepção não se alicerce em uma dinâmica consciente ou até efetiva.

Outra característica deste momento singular: a visibilidade social da política. Como as eleições, em situação democrática, acontecem periodicamente, este momento torna-se esperado socialmente, agendado antes de tudo por mecanismos do próprio campo político. Mais que isto, elas adquirem um caráter eminentemente público e publicizado, porque pretendem a participação de um contigente significativo da população e porque apresentam-se percebidas com atenção e interesse, pois nesse momento talvez mais que nunca se acredita em alguma possibilidade de participar e intervir no governo da sociedade. Periodicidade, ritmo acelerado, caráter público, esforço de publicização, atenção e interesse garantem, deste modo, um agendamento temático manifesto e uma visibilidade especial no momento eleitoral para a política na sociedade.

Não parece estranho, nem casual que o episódio eleitoral seja muitas vezes traduzido como festa e/ou solenidade, como cerimônia que, tendo um grau de excepcionalidade, requer ser vivida de maneira diferente da vida ordinária. Este caráter 
festivo ou solene apenas torna manifesto a singularidade das eleições como momento especial da política.

A realização de eleições implica no acionamento de inúmeros componentes da política formatados na modernidade, tais como candidaturas, programas e partidos. Estes últimos, por exemplo, foram criados como instrumentos apenas eleitorais, sem vida e estrutura permanentes ${ }^{2}$. Além disto, a eleição exige atos de campanha: comícios, inicialmente em ambientes fechados e depois abertos; passeatas; caravanas e embate corpo à corpo. André Jardin, por exemplo, descreve a pré-campanha realizada de porta à porta por Tocqueville com base em um lista de 627 eleitores, para se eleger deputado na circunscrição de Valognes, através do voto censitário, ainda vigente em 1839. A campanha, além disto, exige materiais políticos específicos: documentos, panfletos, cartazes, símbolos e jingles. Em sua versão moderna, ela acontece em espaços fechados ou, com a universalização do número de eleitores, abertos. As ruas e praças tornam-se os espaços (geográficos) por excelência da disputa eleitoral, auxiliados de modo incipiente pela nascente imprensa, com sua limitada repercussão, pelo menos, até meados do século XIX.

Independente da amplitude da presença da imprensa, as eleições já na época moderna podem ser caracterizadas como um "foro comunicativo", no dizer de Alejandro Muñoz Alonso (1989, p.129-150), pois, como momento singular da política, elas exigem de todos os seus atores - desde os conservadores aos revolucionários - um admirável investimento em comunicação, através do acionamento de uma plêiade de estratégias, dispositivos e instrumentos. Afinal, trata-se de comunicar idéias e propostas, convencer, sensibilizar, emocionar. Enfim de mobilizar mentes e corações em uma disputa do poder político na sociedade. E tal embate acontece acordado em normas e, dado fundamental, realizado em ambiente público, buscando reconectar o sistema político e a população, oxigenando-o através da avaliação, da decisão e inclusive da participação dos cidadãos.

Deste modo, toda e qualquer eleição, desde o instante em que os direitos de cidadania foram conquistados no mundo moderno, assume esse caráter de disputa comunicacional, mesmo quando inexistem mídias, em perspectiva relevante. A intensa requisição da comunicação em uma situação vital da política, como acontece com as eleições, propicia assim uma conjuntura especialmente privilegiada para o estudo da comunicação e de suas relações com a política.

\section{Uma nova circunstância societária e comunicacional}

Um dos desafios mais essenciais para pensar a comunicação na atualidade, sem dúvida, diz respeito à rigorosa compreensão do lugar ocupado pela comunicação, especialmente em sua versão midiática, no mundo contemporâneo. O imprescindível tema

\footnotetext{
${ }^{2}$ Os partidos no sua atual concepção de organização política com vida e estrutura permanentes somente nascem com os partidos operários social-democratas. Ver CERRONI (1982).
} 
da incidência da comunicação na sociabilidade e das modalidades de sua conexão com a contemporaneidade tem mobilizado um plural e dissonante núcleo de pensadores da atualidade. Apesar da diversidade de concepções teóricas e ideológicas, um dado comum aparece como fundamental para a investigação e para um novo enquadramento dos estudos: a compreensão da contemporaneidade como uma sociedade transbordante de comunicação e de informação.

Torna-se necessário, ainda que de modo bastante sucinto, nomear a nova circunstância societária e explicitar seus requisitos. Tenho sugerido entender 0 contemporâneo como Idade Mídia $^{3}$. Isto é, como uma sociabilidade estruturada e ambientada pela comunicação, especialmente em sua versão midiatizada.

A comunicação adquire um status estruturante na contemporaneidade porque torna-se dispositivo essencial para a realização do capital, para o conhecimento da atualidade e para costurar em rede o mundo contemporâneo, constituindo assim uma singular sociabilidade, composta de espaços geográfico e eletrônico, convivência e televivência, globalidade e localidade, enfim de realidade contígua e telerrealidade.

A onipresença tentacular da comunicação e sua manifesta exposição através da permanente fabricação e mediação de sentidos pela mídia constitui a singular ambiência da contemporaneidade. Imprescindível então, construir parâmetros que busquem elucidar a comunicação como ambiente, como tessitura onipresente que acolhe e envolve o ser e o estar no mundo na atualidade, como uma quase e segunda "natureza" justaposta que trança a sociabilidade contemporânea.

Para definir a sociedade como estruturada e ambientada pela comunicação, podem ser enumerados, sem um ordenamento hierárquico, alguns requisitos, que, em situações dadas, devem servir como indicadores acerca da pertinência e da sintonia dessa nomeação a uma determinada sociedade. Tais variáveis devem ser consideradas, constatadas e mesmo mensuradas para tornar possível a caracterização de uma sociabilidade como Idade Mídia.

Os requisitos propostos podem ser sinteticamente enumerados nos seguintes tópicos: 1. Expansão quantitativa da comunicação, principalmente em sua modalidade midiatizada, na sociedade estudada, facilmente constatada através de dados sobre números dos meios disponíveis, tais como: quantidade das tiragens e audiências, dimensão de redes em operação etc.; 2 . Diversidade das novas modalidades de mídias presentes no espectro societário, observada através da complexidade da "ecologia da comunicação", das modalidades diferenciadas de mídias existentes e da história recente de sua proliferação e diversificação; 3. Papel desempenhado pela comunicação midiatizada como modo (crescente e até majoritário) de experenciar e conhecer a vida, a realidade e o mundo, retido através de dispositivos e procedimentos, qualitativos e quantitativos, a exemplo do número de horas que os meios ocupam no cotidiano das

\footnotetext{
${ }^{3}$ Para uma elaboração mais detalhada ver RUBIM (2000).
} 
pessoas; 4. Supremacia da cultura midiatizada sobre os outros circuitos culturais existentes, a exemplo do escolar-universitário e do popular. Nesse caso deve ser analisada a presença e a abrangência das culturas midiáticas como circuito cultural, que organiza e difunde socialmente comportamentos, percepções, sentimentos, ideários e valores; 5. Ressonâncias sociais da comunicação midiatizada sobre a produção da significação (intelectiva) e da sensibilidade (afetiva), sociais e individuais; 6. Dominância da mídia como esfera de publicização (hegemônica) na sociabilidade estudada, dentre os diferenciados "espaços públicos" socialmente existentes, articulados e concorrentes. Tal prevalência pode ser constatada através de estudos acerca das modalidades de publicização e suas eficácias; 7. Mutações espaciais e temporais provocadas pelas redes midiáticas, na perspectiva de forjar um vida planetária e em tempo real e 8. Crescimento vertiginoso dos setores voltados para a produção, circulação, difusão e consumo de bens simbólicos, além da ampliação (percentual) dos trabalhadores da informação e da produção simbólica no conjunto da população economicamente ativa.

Enfim, todas essas variáveis - e certamente outras possíveis de elaborar -, operando em uma dinâmica certamente desigual e combinada, devem tornar precisa a delimitação rigorosa das fronteiras de uma nova circunstância societária, a sociedade estruturada e ambientada pela mídia. Mais que isto, o elenco de todas essas facetas, transtornadas pela mídia, deve confirmar e permitir a mensuração e a gradação deste ambiente transbordante de comunicação, que tece e envolve o estar no mundo no espaço/tempo presente, além de apontar as possibilidades de aprofundamento em radicalidade dessa teia midiática no futuro próximo.

A incidência da comunicação não apenas estrutura e ambienta a nossa singular contemporaneidade. Ela afeta em profundidade a configuração da sociabilidade atual, pois ela se vê composta e perpassada por "marcas" possibilitadas pela mídia, tais como o espaço eletrônico, a televivência e globalização. O espaço eletrônico, engendrado pela revolução das comunicações em rede, emerge como registro quase desmaterializado, como espaço sem território, mas que permite virtualizações e atualizações contínuas. A televivência, viabilizada pela mídia, pode ser definida como uma vivência à distância, descolada do lugar e desprendida da presença; como capacidade de vivenciar um ausente, tornado (simbolicamente) presente, em tempo real, através de signos. A globalização, ensejada pelas redes de comunicação e informação, caracteriza-se pela cotidiana disponibilização de um fluxo de signos e sentidos provenientes de uma extração global e não apenas de um local contíguo, como anteriormente.

A mídia, ao consumar um espaço eletrônico em rede, povoado de televivências em abrangência globalizante, em verdade, constrói uma outra e nova dimensão constitutiva da sociabilidade contemporânea, a qual se sugere denominar de telerrealidade, expressão empregada por Muniz Sodré (1984, p.32-41) no seu livro $A$ Máquina do Narciso. Tele, para recordar sua inerente noção de distância e apontar a possibilidade do distante ser apreendido, transportado e transformado (simbolicamente) 
em acontecimento próximo, em algo que ganha um sentido instantâneo e passa a compor o cotidiano como componente inerente à vivência contemporânea. Realidade, para lembrar que esta dimensão de sociabilidade, configurada simbolicamente por imagens, palavras, sons, deve ter sempre afirmado seu estatuto de realidade.

O conceito de telerrealidade deve servir, por conseguinte, para nomear uma nova e contemporânea dimensão de sociabilidade que se distingue da realidade, tradicionalmente concebida como territorialidade (geográfica), localidade, proximidade, materialidade, presença e convivência. Telerrealidade aparece como nova formatação da realidade, possibilitada agora por espaços e tempos integrados em rede eletrônica e associada às noções de desterritorialização, globalidade, distância, espaço planetário, desmaterialização, não presencialidade, (tele)vivência e tempo real.

Mas a sintonia com uma resignificação radical da comunicação e de sua conexão com a contemporaneidade não pode, de modo algum, deixar de tornar problemática esta relação e, pior, fazer retornar uma atribuição desmedida de poderes à comunicação midiática. Não se pactua com esta apressada e equivocada solução. Antes disto, pretende-se mapear as novas circunstâncias nas quais a composição entre comunicação e sociedade se realiza na atualidade. Ou seja, descritas as novas condições, caberá, com o campo de forças então conformado, analisar como se comportam as duas esferas sociais e como se efetua seu enlace, sem qualquer tentação de definir uma dominância, um conflito ou uma complementariedade, a priori.

Da afirmação dessa nova circunstância sócio-comunicacional, decerto não podem derivar, sem mais, posturas preconcebidas e fixadas acerca da predominância do poder da comunicação sobre outros campos sociais. A dinâmica dos deslocamentos de poder entre os campos da comunicação e as outras esferas sociais, antes de ser resolvida previamente, constitui-se em objeto privilegiado de investigação. Mais que isso, como premissa deste estudo descarta-se uma dominância unilateral e persistente de qualquer uma dessas esferas. Afirma-se, pelo contrário, a disputa e alternância de predomínios da política ou da comunicação em situações dadas, em campos de força determinados.

Esta nova circunstância, ao reorganizar a sociabilidade, configura um novo ambiente, no qual agora acontecem as eleições. Natural imaginar que nelas devem acontecer transmutações, muitas já historicamente produzidas, muitas ainda em andamento e muitas por serem inauguradas. Tais alterações, certamente profundas, buscam sintonizá-las, não sem tensões, com esta nova circunstância societária, com as complexas convergências que se manifestam; com os múltiplos espaços que se abrem, metaforicamente nomeados aqui de rua e tela; com a diversidade de possibilidades de vivências que afloram; com as contradições e impasses surgidas com a glocalidade, conjunção tensa e atual entre globalidade e localidade; enfim com os singulares e problemáticos contornos adquiridos pela sociedade contemporânea. 


\section{Eleições e (Idade) Mídia}

Obrigatório colocar a reflexão acerca das relações entre eleições e comunicação nesta nova constelação analítica, que tem como horizonte a idéia de que se vive hoje uma atualidade, na qual a sociabilidade encontra-se estruturada e ambientada pela mídia. Expressões como "campanhas modernizadas", esboçadas por Paolo Mancini e David Swanson ${ }^{4}$, devem ganhar sentido mais profundo apenas se referidas a esta nova circunstância societária e comunicacional.

A questão de quais as novas configurações das eleições na Idade Mídia se instala no cerne desta reflexão. Ainda que as respostas à crucial questão não estejam plenamente formuladas, posto que este processo encontra-se em desenvolvimento, podese propor algumas possibilidades e hipóteses, acompanhando formulações de autores que, diversas vezes, percebem tais mutações, mesmo que de maneira fragmentária, porque, muitas vezes, não conseguem inserir essas novas configurações na constelação sócio-comunicacional que lhes dá um sentido mais profundo e rigoroso.

Alejandro Alonso, por exemplo, estudando campanhas eleitorais e mídia, chega à seguinte constatação: Pode se dizer que se durante o século passado e o primeiro terço do $X X$ os comícios eram a essência de qualquer campanha eleitoral, agora esse papel central é desempenhado pelos meios e, especialmente, pela televisão. (Alonso, 1989, p.136)

O autor chega inclusive a escrever que, dentre os recursos de uma campanha eleitoral na atualidade, as mídias, transformadas em grande foro, apresentam-se como o mais importante. Independente de um concordância plena com essas formulações, o autor indica um deslocamento fundamental no espaço privilegiado e no eixo central das campanhas políticas: do comício na rua para o programa na tela. Não que os comícios deixem de existir ou de ter papel eleitoral significativo, mas o cerne da campanha passa a ser o espaço eletrônico, especialmente o televisivo, devido à sua abrangência e seu potencial impacto.

Este deslocamento não pode, no entanto, ser apreendido nem como submissão plena da política à lógica midiática, nem como desvirtuação da política. Antes deve ser pensado como adequação da política à nova situação de uma sociabilidade, estruturada $e$ ambientada pela mídia. A adequação certamente não se faz sem novidades, sem novas conformações da relação entre comunicação e política, sem novas dificuldades e possibilidades para a democracia e inclusive sem novos enigmas a serem estudados, diagnosticados e resolvidos. Afirma-se assim esse caráter problemático, porque carregado de tendências em disputa, de tensões, de possibilidades em aberto, da nova situação, mas nunca uma resolução já dada, algo determinado a priori.

A novidade não está restrita ao emblemático deslocamento acontecido no cerne da campanha da rua para a tela, mas igualmente revela-se em uma formidável mutação

\footnotetext{
${ }^{4}$ A noção de "campanhas modernizadas" está esboçada em MANCINI \& SWANSON, 1996. p. 1-26.
} 
que ocorre na formatação adquirida pelo tema das eleições na tela. Em uma circunstância societária anterior, as eleições se apresentam na embrionária mídia então existente, especialmente jornais e depois rádio, quase completamente sob o formato de cobertura de acontecimentos ocorridos em espaços geográficos e convivenciais, tais como comícios, panfletagens, visitas, passeatas, conversas, atos, etc. Hoje a visibilidade do momento eleitoral na tela não se restringe, mas transcende de maneira exponencial o formato jornalístico da cobertura e divulgação dos atos eleitorais.

A rigor, a dimensão de visibilidade eleitoral privilegiada na tela configura-se em novos formatos: os programas eleitorais, em suas diferenciadas modalidades de acordo com as tradições e legislações eleitorais dos vários países, e os debates eleitorais, especialmente. Tais formatos - oriundos de uma intervenção da política (programas eleitorais veiculados na mídia) e de uma iniciativa da mídia (debates eleitorais) - já não ganham sentido por sua dependência e por uma remissão aos acontecimentos originados no universo geográfico-convivencial, mas tornam-se relevantes pela produção de novos acontecimentos políticos, provenientes e localizados na própria tela. Através desta "autonomização" na produção de acontecimentos e de sua dinâmica, o espaço eletrônico se transforma ele mesmo em um lugar essencial de disputa política-eleitoral.

Nessa perspectiva, a tela não somente se apresenta como espaço mais significativo, que faz surgir novos formatos de atuação política, mas possibilita a produção de novos acontecimentos políticos, com grande potencial de impacto, que se autonomizam frente a realidade contígua e se inscrevem na telerrealidade. Tais atos políticos passam a ser essenciais para a campanha, pois fazem agregar a ela um novo patamar de disputa, no qual ocorre a competição eleitoral. A capacidade de produzir eficazmente "fatos" políticos em uma campanha, sejam eles instalados em espaços geográficos ou principalmente eletrônicos, aparece com diferencial importante do embate político.

A tela - objeto-síntese destes espaços eletrônicos conectados em redes emerge assim como novo e privilegiado espaço de disputa a ser ocupado pela política. Ela, antes habitante habitual dos espaços geográficos, se vê desafiada a operar de maneira crescente em registro eletrônico. Cabe relembrar que a telerrealidade, na perspectiva aqui anunciada, deve ser considerada como tendo estatuto de realidade, como dimensão indissociável da sociabilidade contemporânea, não comportando, em nenhuma hipótese, sua depreciação, por assimilação à irrealidade, a uma realidade de segundo grau ou a qualquer outra modalidade hierarquicamente inferiorizada de realidade, sem mais.

Em resumo, o desafio colocado à política e especificamente às campanhas eleitorais pode ser formulado como necessidade de novas configurações que, adequadas, invadam estes novos e privilegiados espaços sociais, realizados a um modo televivencial, e que interajam com as modalidades anteriores de realização das eleições, pertinentes à disputa convivencial. 
No momento eleitoral, como foi visto, surgem historicamente novos formatos na tela para o exercício da política. Os horários e debates eleitorais, assumindo formas variadas, agregam-se aos noticiários e outras faixas - por vezes insuspeitas como programas de humor, telenovelas, shows de variedades etc - da programação, todas elas passíveis de serem perpassadas pela política. Tais espaços eletrônicos, em decorrência de sua singularidade e novidade, têm suas exigências e requisitos. A política deve obrigatoriamente compreendê-los para poder se locomover nestes espaços de maneira simultaneamente adaptada às "linguagens" da tela e adequada à sua lógica imanente. A diferença entre lógicas, provenientes de campos sociais distintos, pode se manifestar neste instante em todo esplendor como complementariedade ou tensão. A mídia, ao exigir respeito às suas "linguagens", indispensáveis a uma tradução e trânsito necessários ao seu espaço, pode subrepticiamente exportar sua lógica específica, repleta de interesses próprios, buscando impor seu poder ao campo político. Este, na contramão, ao assimilar a "linguagem" da mídia, qualificando sua ocupação do ambiente eletrônico e preservando sua lógica imanente, pode instrumentalizar o campo das mídias, buscando submetê-lo a seu poder de decisão.

A profissionalização das campanhas eleitorais responde a esta nova circunstância e aos requisitos da tela, ainda que suas "linguagens" não estejam confeccionadas em plenitude, como se observa, de forma escancarada, com relação à Internet. Dentre as preocupações centrais da pesquisa em andamento - "Novas configurações da política na Idade Mídia" - encontra-se a investigação de como a política tem se realizado nas novas mídias, entre elas, a Internet. Nesta perspectiva, análises empíricas da convergência política e Internet têm sido desenvolvidas, estudando-se os sites partidários brasileiros, em momentos políticos não-eleitorais e eleitorais, quando se pesquisam também os sites de candidaturas. A investigação destas novas mídias aparece com fundamental, pois nelas ainda não se formatou e convencionou um "padrão gramatical" próprio, adequado ao suporte sócio-tecnológico já existente, ele mesmo em dinâmica mutação.

A profissionalização da campanha decorre das exigências do novo espaço a ser ocupado, da especificidade de suas "linguagens", mas também de novos componentes, que surgem e somente adquirem sentido nas sociedades ambientadas pela mídia, tais como as sondagens de opinião, em suas mais variadas modalidades. Estes novos componentes, que se somam aos recursos tradicionais da política, forjada na modernidade, também exigem profissionais especializados.

Fernando Azevedo, em texto acerca da modernização das campanhas eleitorais no Brasil, propôs quatro indicadores deste processo: a profissionalização da campanha; o uso das sondagens de opinião; a utilização da mídia, em especial da televisiva e a personalização da campanha eleitoral. Todos eles, inclusive este último tópico, realçam novas formatações de realização da política, mais especificamente em seu momento eleitoral em uma situação em que a mídia e as novas circunstâncias societárias e comunicacionais já estão instaladas de modo substantivo. A personalização das 
campanhas, malgrado os componentes políticos inerentes a tal movimento no Brasil (tradição de uma política pessoalizada, presidencialismo, força dos cargos executivos etc.), encontra no formato imagético da tela um atributo e um reforço fundamentais para o incremento da personalização, pois a imagem, ao invés de tender ao abstrato, vive da capacidade expressiva de captar a singularidade e não a generalidade.

Mas as novas configurações e formatos da campanha eleitoral não se restringem à tela. A rua - compreendida como síntese dos espaços geográficos tão característicos da política na modernidade - e a convivência encontram-se na atualidade assaltadas e irremediavelmente contaminadas pela política midiatizada, transportada pela tela. Marshall McLuhan, a este respeito, pontificou: Surgiu uma nova forma de vida política em que a sala de estar se converte em colégio eleitoral. (McLuhan, apud, Alonso, 1989, p.129)

Nesta perspectiva, os espaços geográficos compartilhados publicamente e até aqueles privados - como na citação acima - sofrem o impacto de sua fricção com os espaços eletrônicos. A tela conecta e incorpora, em determinado sentido, a rua, (re)significando-a, ao apanhá-la em sua rede, como acontecimento para ausentes, como (tele)realidade. Mesmo os atos de rua não capturados se (re)semantizam, pois a onipresença da teia midiática, ao envolver tudo e todos, induz a que os atos busquem produzir sentido não apenas para seu entorno físico-social, mas também para um virtual (sempre possível e muitas vezes desejado) compartilhamento à distância, espacial e temporal. Comícios, passeatas, carreatas, outros atos político-eleitorais e até mesmo o simples corpo-à-corpo cada vez mais pretendem e absorvem um "efeito de mídia". Tal "efeito", quando construído de modo intencional e não inconsciente, pode acionar diferenciados dispositivos de produção: espetacularização, critérios de noticiabilidade, contradições e contrastes inscritos na realidade, além de outros procedimentos possíveis.

A probabilíssima reconfiguração dos atos retidos na metáfora rua e dos atos convivenciais nas eleições contemporâneas pode obedecer a pretensões muito diferentes. Pode significar um amesquinhamento ou uma dinamização destes atos e dos dispositivos de produção de sentido, inscritos na tela. Pode ainda pretender um ruptura ou uma sintonia fina entre tela e rua. Um análise de campanhas eleitorais parece indicar que uma estratégia de imbricamento forte entre tela e rua, pode dinamizá-las mutuamente e em seqüência potencializar e politizar com mais vigor a campanha eleitoral.

Os estudos da interação entre eleições e mídia, perpassado por todas estas convergências e tensões características da contemporaneidade, pelas dimensões de tela e rua e seu entrelaçamento, têm uma ampliada possibilidade de enquadramentos e de objetos específicos. Um tentativa de delinear esse campo, certamente incompleto, deve elencar os estudos voltados: 1. aos discursos político-eleitorais elaborados; 2 . às estratégias político-eleitorais desenvolvidas; 3 . aos formatos político-eleitorais acionados; 4. aos cenários político-eleitorais configurados, aqui incluídas as agendas e tematizações; os atores e suas imagens; as atmosferas e climas sociais e 5. às dinâmicas de conflito e integração existentes nas eleições entre os campos da política e das mídias. 
Por tudo que foi dito neste e nos tópicos anteriores pode-se concluir que as eleições, enquanto momento singular da política, assim como a política em geral, sofrem transmutações significativas quando inscritas na nova sociabilidade. No caso das eleições tomadas aqui como emblemáticas dessas transformações, pode-se constatar: 1. o deslocamento do espaço privilegiado da rua para a tela, especialmente em eleições majoritárias; 2. o advento de novos formatos políticos seja na tela, seja na rua e por fim 3. a aparição, como possibilidade produtiva, de novos acontecimentos políticos, ensejados na tela e em uma perspectiva específica autonomizados frente à campanha de rua, cuja produção torna-se crucial para a campanha eleitoral. Enfim: novas configurações das eleições sintonizadas com as novas configurações assumidas pela política em uma sociedade estruturada e ambientada pela comunicação e pela mídia.

\section{BIBLIOGRAFIA}

ALONSO, Alejandro Muñoz.(1989) Campañas electorales y medios de comunicación. In: Política y nueva comunicación. El impacto de los medios en la vida política. Madrid, $\overline{\text { Fundesco, }}$ 1989.

AZEVEDO, Fernando. (1998) Espaço público, mídia e modernização das campanhas eleitorais no Brasil. Texto apresentado na VII Encontro Anual da Associação Nacional dos Programas de PósGraduação em Comunicação - COMPÓS. São Paulo/PUC, 01 a 05 de junho de 1998, 10p.

BARREIRA, Irlys. (1998) Chuva de papéis. Rio de Janeiro, Relume Dumará.

BOURDIEU, Pierre. (s.d.) A representação política. Elementos para uma teoria do campo da política. In: . O poder simbólico. Lisboa/Rio de Janeiro, Difel/Bertrand Brasil, p. 163-207.

CERRONI, Umberto. (1982) Teoria do partido político. São Paulo, Ciências Humanas.

JARDIN, André. (1984) Alexis de Tocqueville. Paris, Hachette.

MANCINI, Paolo \& SWANSON, David. (1996) Politics, media and modern democracy: introduction. In: SWANSON, David (org.) Politics, media and modern democracy: an international study of innovations in electoral campaigning and their consequences. Wesport/London, Praeger, p.1-26.

NOHLEN, Dieter. (1995) Elecciones y sistemas electorales. Caracas, Nueva Sociedad.

RUBIM, Antonio Albino Canelas. (1999) Mídia e política no Brasil. João Pessoa, Editora UFPb.

(2000) A contemporaneidade como Idade Mídia. Trabalho aceito para ser apresentado no V Congresso da ALAIC. Santiago do Chile, abril de 2000.

SODRÉ, Muniz. (1984) A máquina do narciso. Rio de Janeiro, Achiamé.

TOURAINE, Alain. (1996) O que é democracia? Petrópolis, Vozes. 